\title{
Perspectives on the Green Climate Fund: Possible Compromises on Capitalization and Balanced Allocation
}

Mathias Fridahl and Björn-Ola Linnér

\begin{abstract}
Finance is at the heart of UN climate diplomacy. Developed countries have pledged to mobilize USD 100 billion annually from 2020 onwards to support climate action in developing countries. Concurrently, the Green Climate Fund (GCF) has been established, expected to become a key player in the climate finance landscape. Through a survey conducted at the 2013 UN Climate Change Conference in Warsaw, this viewpoint presents how respondents representing developed and developing countries' governments envisage the share of the long-term finance pledge (USD 100 billion annually) to be dispensed by the GCF. The respondents' perspectives are related to how they view 1) the mitigation/adaptation ratio in GCF support, and 2) the public/private ratio in financial sources. Respondents from developing countries prefer channeling a substantially higher amount of the long-term finance pledge through the GCF than respondents from developed countries. Since long-term finance is pledged without specifying the mitigation/adaptation ratio, whereas the GCF Board should balance the allocation of its funds between adaptation and mitigation, the extent to which the longterm finance pledge should be governed by the GCF is contentious. This contestation is fueled by the fact that developing countries have a greater say in the allocation of funds from the GCF than from alternative sources of finance for the long-term finance pledge. We suggest that it is time to 1) reformulate the pledge to clarify its mitigation/adaptation ratio, and 2) agree to definitions of key concepts such as 'climate finance' and 'private finance' to allow for more distinct negotiating positions on sources of finance.
\end{abstract}

Keywords: The UN Framework Convention on Climate Change, the Green Climate Fund, the long-term finance pledge, adaptation, mitigation 


\section{Introduction}

Finance is at the heart of efforts to reach a new international climate agreement in Paris in 2015. Several mitigation instruments discussed require financial support from developed to developing countries. In addition, developing countries have increasingly emphasized the need for adaptation support and liability compensation (Huq, Roberts \& Fenton, 2013; Agrawala \& van Aalst, 2008). Yet, the slow progress in scaling up climate finance has amplified long-standing conflict in international negotiations (Gampfer, Bernauer \& Kachi, 2014; Fenton et al., 2014). The climate finance needs are great, while current flows are limited. So far the developed countries' pledge to mobilize USD 100 billion annually, from 2020 onwards, is the most substantial number brought to the negotiating table (Röser et al., 2014). On top of the missing clarity by whom, how, and for what the pledge shall be delivered, how the finance shall be governed remains contested. The lack in clarity on the sources of finance and its administration constitutes a predicament in the climate negotiations.

In this viewpoint, we pinpoint a locus of climate finance conflict by identifying links between what governmental delegates to the UN Framework Convention on Climate Change (UNFCCC) prefer as sources of finance, what the finance should target, and the role of the Green Climate Fund (GCF) to govern the long-term finance pledge. Based on this analysis, we suggest to move forward on finance in the negotiations by specifying the general imprecise commitments to adaptation and mitigation within the scope of the quantified long-term finance pledge first announced in Copenhagen, 2009. Further, specifying the share of public finance of the USD 100 billion annually would also provide clarity and help build trust. 
In 2010, the UNFCCC established the GCF as a new operating entity of the its Financial Mechanism (UNFCCC, 2011: 1/CP.16). In late 2013, the arrangements between the Convention's Conference of Parties (COP) and the GCF Board were agreed, paving the way for operationalizing the Fund (UNFCCC, 2013b). Although the GCF is expected to play a key role in the governance of the long-term finance pledge, how and to what extent remain open questions (Harmeling \& Grießhaber, 2013).

The $19^{\text {th }}$ session of the COP (COP19), conducted in Warsaw in 2013, was expected to agree on both how to mobilize the USD 100 billion per year as well as how to resolve the contended issue of sources of finance and the role of the private sector. These ambitions failed (Fenton et al., 2014; UNFCCC, 2013a). The outcomes of COP20 in Lima in 2014 provided no further clarity (cf. UNFCCC, 2014c). One reason is that the key conflict over how to govern the USD 100 billion pledge remains unresolved; an issue that was already difficult at COP15 in Copenhagen (Dimitrov, 2010).

As noted by Khan \& Roberts (2013), "Inadequate and poorly defined rules on climate finance stand as a major obstacle to building trust between the materially powerful and the vulnerable poor countries" (p. 184). And trust is crucial for an agreement in Paris (Friman, 2013).

Based on responses to the International Negotiations Survey at COP19 in Warsaw in 2013, we report on UNFCCC respondents' opinions of the share of the pledged USD 100 billion that should be governed by the GCF. We do this in the context of their views on: 1) the mitigation/adaptation ratio in GCF support, and 2) the public/private ratio in financial sources. 
The dataset comprises 565 observations. Here, we focus on governmental delegates subdivided according to their being from countries listed in Annex 1 (A1) of the Convention, ${ }^{1}$ understood here as roughly equivalent to developed countries, or all other countries, i.e. non-Annex 1 (NA1) countries, understood here as developing countries. This focus contains 220 valid observations from all UN regional groupings $\left(n_{\mathrm{A} 1}=72\right.$ and $\left.n_{\mathrm{NA1}}=148\right)$.

\section{Capitalization and Balanced Allocation: Governance of the Long-}

\section{term Finance Pledge}

The survey responses reported in Table 1 provide indications as to where we can expect convergence and conflict over the issues raised above.

TABLE 1 COP19 respondents' preferences expressed in mean values [\%]

\begin{tabular}{|c|c|c|c|}
\hline & & \multicolumn{2}{|c|}{ Primary role by Annex } \\
\hline & & $\begin{array}{c}\text { Annex } 1 \\
\text { governmental }\end{array}$ & $\begin{array}{l}\text { Non-annex } 1 \\
\text { governmental }\end{array}$ \\
\hline \multicolumn{2}{|c|}{$\begin{array}{l}\text { Share of the long-term finance } \\
\text { pledge channeled through the GCF }\end{array}$} & $43.6^{\mathrm{a}}$ & $71.0^{b}$ \\
\hline \multirow[t]{2}{*}{ Source: } & Public finance & $56.0^{c}$ & $58.3^{d}$ \\
\hline & Private finance & $44.0^{c}$ & $41.7^{\mathrm{d}}$ \\
\hline \multirow[t]{2}{*}{ Allocation : } & Mitigation & $53.6^{\mathrm{e}}$ & $45.4^{f}$ \\
\hline & Adaptation & $46.4^{\mathrm{e}}$ & $54.6^{\dagger}$ \\
\hline
\end{tabular}

Note: private + public sources as well as allocation between mitigation and adaptation sum to $100 \%$ (i.e. respondents followed the requirement to assume no overlaps). Number of valid observations for: $a=46, b=106, c=47, d=114$, $e=51$, and $f=111$. ${ }^{\star}$ The mean difference is significant at the 0.05 level.

\footnotetext{
${ }^{1}$ Annex 1 includes countries that were members of the Organisation for Economic Co-operation and Development in 1992 and so-called countries with economies in transition.
} 
On sources of finance, the correspondence between A1 and NA1 respondents' preferences indicate a potential for converging understandings. However, for two reasons it may still be difficult to reach consensus: First, the variances in opinions around the mean values are high, implying relatively high shares of the respondents holding extreme positions. In the consensus-oriented UNFCCC regime, these variances may be harder to reconcile than clearly distinct opinions separated by smaller gaps.

Second, the wide variance in responses can be interpreted as reflecting the fact that there is very little clarity on how to define climate finance and how to account for private finance in international climate policy (Stadelmann, Michaelowa, \& Roberts, 2013; UNFCCC Standing Committee on Finance [SCF], 2014). This confusion may lead to situations where negotiators misinterpret each other's positions, which undermines trust.

The respondents' positions on allocating funding to adaptation or mitigation are much more distinct. The divergences are statistically significant. However, the gap between mean values of A1 and NA1 delegates' preferences, i.e. that A1 would like to see $46 \%$ share of adaptation while NA1 desire $55 \%$, is not great. It should be noted that the governing instrument of the GCF set out an important principle: the Fund shall balance the allocation of resources between adaptation and mitigation (UNFCCC, 2012: §6). The GCF Board recently specified this as a 50:50 convergence over time (GCF, 2014). This compromise among Board members resonates among the COP delegates surveyed here.

The largest divergence in positions concerns the extent to which the long-term finance pledge should be channeled through the GCF (cf. Figure 1). A1 governmental 
respondents prefer a lower share (as indicated by a mean of 44\%) whereas NA1 governmental respondents prefer a higher share (as indicated by a mean of 71\%).

FIGURE 1 Share of the long-term finance pledge to be channeled through the GCF: Histogram with governmental delegates' responses binned into 10 equal intervals

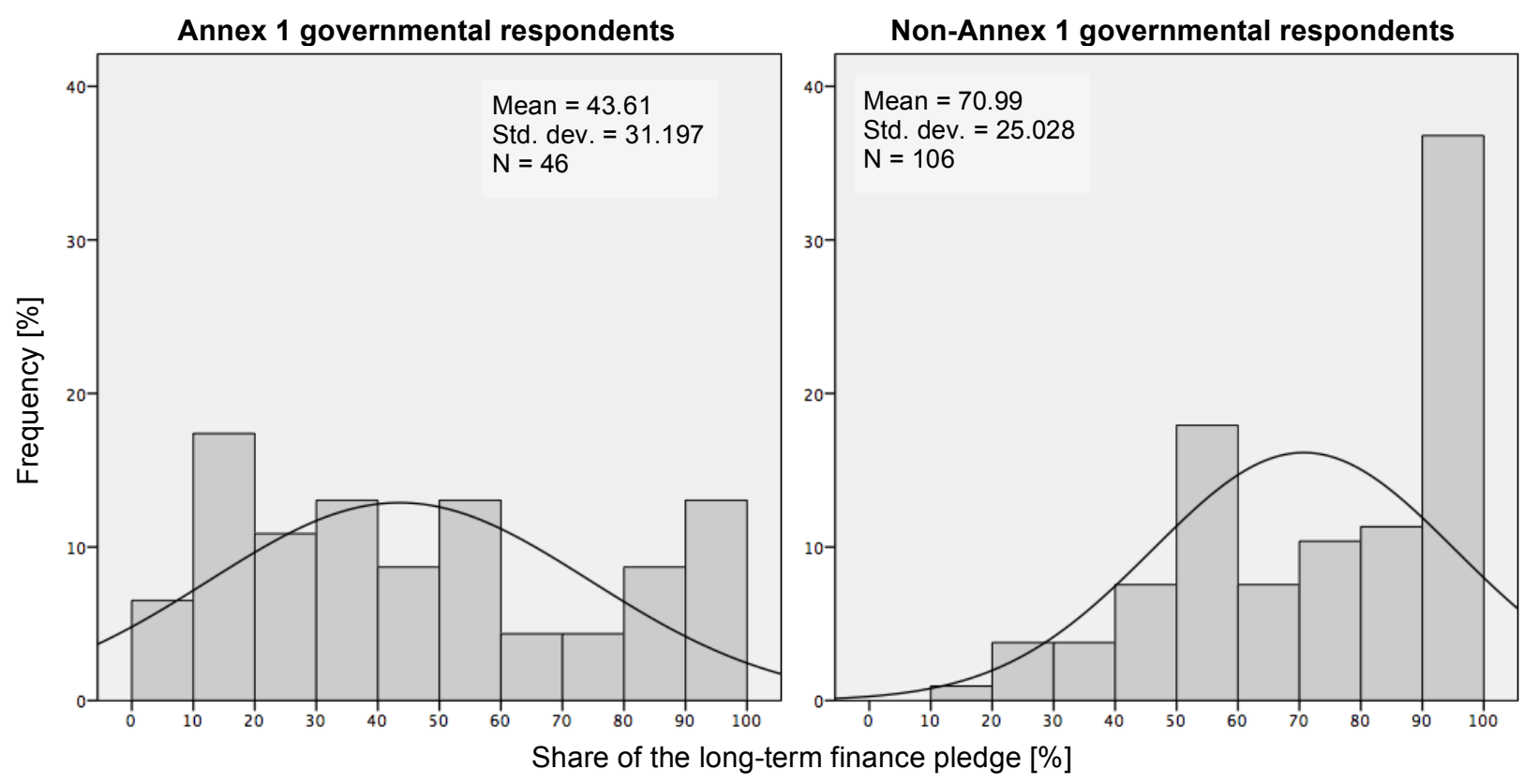

The preference for a low share of the long-term finance pledge being channeled through the GCF among A1 respondents and a high share among NA1 respondents makes sense in the context of how they also want the GCF to prioritize differently when allocating support to mitigation and adaptation. To understand these differences, it is worth reiterating that the share of the USD 100 billion in annual support to adaptation or mitigation is not specified (UNFCCC, 2011: 1/CP.16) while the GCF has to balance the allocation of support between mitigation and adaptation (UNFCCC, 2012: 3/CP.17). A respondent who prefer the GCF to allocate a relatively high proportion of support to adaptation, is more inclined to favor a strong link between the GCF and the USD 100 billion pledge. Whether one is from an A1 or NA1 country does not matter, as a similar 
positive correlation is found in both categories. This indicates that governmental respondents are well aware that if more of the long-term finance with public sources is channeled through the GCF, governments will have to accept that such money is allocated equally to mitigation and adaptation.

Thus, with a focus on mitigation, such as that of A1 respondents, we can expect a higher hesitancy to channel funding via the GCF relative to preferences among NA1 respondents. With a focus on adaptation, such as that of NA1 respondents, it makes sense to shift financial support from a context that has favored funding mitigation actions over adaptation actions to a context that seeks a 50:50 balance of disbursement between adaptation and mitigation. Placing the long-term finance pledge in a context that acknowledges adaptation funding in parity to mitigation funding is a step in the right direction for respondents who emphasize the need for adaptation support. This question is particularly pertinent at a time when the Adaptation Fund (AF) under the Kyoto Protocol is drying up as a result of halted investments in the Clean Development Mechanism (CDM), halted investments that also reduce the capitalization of the AF since its largest historical source of funding has been from a share of the proceeds of CDM project activities (Persson \& Remling, 2014; Ciplet, Roberts, \& Khan, 2013; UNFCCC, 2014a).

The positions of NA1 and A1 governmental respondents surveyed at Warsaw were similar to positions held at COP20 in Lima in 2014. Negotiators at Lima spent a considerable time on whether or not the Paris agreement should explicate that mitigation and adaptation should have legal parity, and if so, what it means. In relation to long-term finance, COP20 also repeated the decision from COP19 in Warsaw to call on developed country Parties to channel a substantial share of public climate funds to 
adaptation activities (UNFCCC, 2014b, 2014c), yet no agreement was possible on how the term "substantial" should be interpreted. Further, the NA1 governments cautioned against "mitigation centric" negotiations towards a Paris agreement (IISD, 2014: p. 43).

At least two additional facts can help explain the divergence in positions on the extent to which the long-term finance pledge should be channeled through the GCF: 1) the GCF Board has equal representation of developed and developing country representatives, and 2) the Board has full responsibility for funding decisions. This means that developing country governments have a much higher influence on funding decisions in the GCF Board than they have over other sources of funding for the long-term finance pledge, such as private sources or bilateral support. In addition to NA1 governmental respondents' prioritization of adaptation, developing countries relatively greater influence on funding decisions in the GCF than elsewhere also explains their preference that the GCF should govern a high amount of the long-term finance pledge.

This leads us to conclude that contention over how much of the long-term finance pledge that should be governed by the GCF foremost concerns how much of that finance should be earmarked for adaptation. Those who strongly prioritize mitigation are also much less willing to let the GCF handle any substantial share of the long-term finance pledge. The contention has much less to do with the ability of the GCF to use public finance to facilitate private investments.

\section{Recommendations}

The disagreement on the GCF's ability to govern long-term finance pledge very much boils down to the mismatch between the Copenhagen long-term finance pledge not 
specifying to what extent it targets mitigation or adaptation and the GCF requirement to balance the allocation of its resources to both mitigation and adaptation.

NA1 governmental respondents, which in general accentuate support for adaptation, also prefer that the GCF be allowed to govern a substantially higher amount of the longterm finance pledge than A1 governmental respondents, which in general accentuate mitigation support. Further, that the GCF Board also provides a forum where NA1 countries can influence funding decisions on equal footing to A1 countries also helps explain why NA1 governmental respondents prefer that the GCF should govern a higher amount of the long-term finance pledge than A1 governmental respondents. Our survey results indicate that if $\mathrm{A} 1$ governments have a greater say in allocating funding, slightly less support would flow to adaptation actions. We suggest moving forward on finance in the negotiations by clarifying what share of the long-term finance pledge that is intended for adaptation.

We also suggest that, as much as possible, the GCF Board clarifies its role in the climate finance landscape, which in turn will make it easier for COP negotiators to agree on the issue of governance of the long-term finance pledge. The GCF Board's recent clarification that balanced allocation means a 50:50 distribution of the Fund's support to mitigation versus adaptation is helpful. With this clearer interpretation, the COP will be better informed and equipped to address the more contentious questions of whether and to what extent the long-term finance pledge should be channeled through the GCF.

A clearer definition of climate finance as well as what can be included as private finance would be helpful too, allowing for governments to have more distinct positions on sources of finance. Since the survey responses indicate high convergence between NA1 and A1, as well as high variance within the groups of NA1 and A1 respondents, on 
sources of finance, seeking clarity on definitions in order to reduce the variance in views is likely a first step towards striking constructive compromises. The work of the UNFCCC's Standing Committee on Finance, recently finalizing its first Biennial Assessment and Overview of Climate Finance Flows (SCF, 2014), could be informative in this regard. Clearer definitions provide a foundation for specifying the share of public finance of the USD 100 billion annually, which would also provide clarity and help build trust.

\section{References}

Agrawala, Shardul, \& Aalst, Maarten van. (2008). Adapting development cooperation to adapt to climate change. Climate Policy, 8(2), 183-193.

Buchner, Barbara, Herve-Mignucci, Morgan, Trabacchi, Chiara, Wilkinson, Jane, Stadelmann, Martin, Boyd, Rodney, ... Micale, Valerio. (2013). The Global Landscape of Climate Finance 2013. Climate Policy Initiative: San Fransisco.

Ciplet, David, Timmons, Roberts J., \& Khan, Mizan R. (2013). The Politics of International Climate Adaptation Funding: Justice and Divisions in the Greenhouse. Global Environmental Politics, 13(1), 49-68.

Dimitrov, Radoslav S. (2010). Inside UN Climate Change Negotiations: The Copenhagen Conference. Review of Policy Research, 27(6), 795-821.

Fenton, Adrian, Wright, Helena, Afionis, Stavros, Paavola, Jouni, and Huq, Saleemul. (2014). Debt relief and financing climate change action. Nature Clim. Change 4(8): 650-653.

Friman, Mathias. (2013). Historical responsibility: Assessing the past in international climate negotiations. Linköping Studies in Arts and Science No. 569. Linköping: Linköping University - Water and Environmental Studies.

Gampfer, Robert, Thomas Bernauer, and Aya Kachi. (2014). Obtaining public support for North-South climate funding: Evidence from conjoint experiments in donor countries. Global Environmental Change 29: 118-126.

GCF. (2014). Decisions of the Board - Sixth Meeting of the Board. Bali 19-21 February 2014. Gcf/B.06/18.

Harmeling, Sven and Grießhaber, Linde. (2013). How can the Green Climate Fund initiate a paradigm shift? Climate and Development Knowledge Network: London.

Huq, Saleemul, Roberts, Erin, and Fenton, Adrian. (2013). Loss and Damage. Nature Climate Change 3(11): 947-949.

IISD. (2014). Summary of the Lima Climate Change Conference: 1-14 December 2014. Earth Negotiations Bulletin 12(619), 1-46. New York: International Institute for Sustainable Development.

Khan, Mizan R, \& Roberts, J Timmons. (2013). Adaptation and international climate policy. WIREs Climate Change, 4(3), 171-189.

Persson, Åsa, \& Remling, Elise. (2014). Equity and efficiency in adaptation finance: initial experiences of the Adaptation Fund. Climate Policy 14(4): 488-506. 
Röser, Frauke, Hagemann, Markus, Höhne, Niklas, Ward, Murray, Bosquet, Michel, Fekete, Hanna, ... van Toledo, Gideon. (2014). Global Climate Finance Needs: Literature review and preliminary analysis of low emission investment plans associated with mitigation pledges made by developing countries in the UNFCCC negotiations. Ecofys: Berlin and Cologne.

Stadelmann, Martin, Michaelowa, Axel, \& Roberts, J Timmons. (2013). Difficulties in accounting for private finance in international climate policy. Climate Policy, 13(6), 718-737.

Sterk, W., Luhmann, H.-J., \& Mersmann, F. (2011). How Much Is 100 Billion US Dollars? Climate Finance between Adequacy and Creative Accounting International Policy Analysis. Berlin: Friedrich Ebert Stiftung, Global Policy and Development.

UNFCCC. (2011). COP16: Report (addendum 1), Cancún 2010. FCCC/CP/2010/7/Add.1.

UNFCCC. (2012). COP17: Report (addendum 1), Durban 2011. FCCC/CP/2011/9/Add.1.

UNFCCC. (2013a). COP18: Report (addendum 1), Doha 2012. FCCC/CP/2012/8/Add.1.

UNFCCC. (2013b). COP19: Arrangements between the Conference of the Parties and the Green Climate Fund. Decision 5/CP.19, FCCC/CP/2013/10/Add.1.

UNFCCC. (2014a). CDM Insights: intelligence about the CDM at the end of each month. Retrieved 19-02-2014, from http://cdm.unfccc.int/Statistics/Public/index.html

UNFCCC. (2014b). COP19: Report (addendum 1), Warsaw 2013. FCCC/CP/2013/10/Add.1

UNFCCC. (2014c). COP20: Advance unedited version of the decision on Long-term climate finance, Lima 2014. Retrieved 30-12-2014, from http://unfccc.int/files/meetings/lima_dec_2014/decisions/application/pdf/auv_ cop20_ltf.pdf

SCF. (2014) UNFCCC Standing Committee on Finance: 2014 Biennial Assessment and Overview of Climate Finance Flows Report. Bonn: UNFCCC. Retrieved 30-12-2014, from

http://unfccc.int/files/cooperation_and_support/financial_mechanism/standing_ committee/application/pdf/2014_biennial_assessment_and_overview_of_climate _finance_flows_report_web.pdf 